\title{
Obstetric and perinatal aspects in patients with congenital heart diseases
}

"Leonor Mendes de Barros" Maternity, Heart Institute of the University of São Paulo - São Paulo, Brazil

The benefits of surgical treatment for patients with congenital heart disease in relation to pregnancy are still controversial. We studied 48 pregnant women (mean age $=25$ years) with surgically-corrected congenital heart diseases (Group 1). This included 15 cyanotic diseases: Fallot's tetralogy ( 11 cases); Ebstein's anomaly ( 2 cases); transposition of the great arteries ( 1 case); and double outlet of the right ventricle ( 1 case). We compared them to 52 pregnant women (mean age $=26$ years) with untreated congenital heart diseases, which included 11 cases of Eisenmenger's syndrome (Group 2). Group 2 showed a higher incidence of maternal death (12 vs. 0 percent; $p=0.01$ ), perinatal mortality ( 15 vs. 0 percent; $p=0.01$ ) and prematurity ( $32 \mathrm{vs.} 7$ percent; $p=0.01)$. Spontaneous abortion ( 4 vs. 10 percent), Caesarean deliveries ( 48 vs. 66 percent) or growth retardation ( 13 vs. 28 percent) did not present any significant differences between these groups. Surgical treatment in patients with heart diseases is associated with a better maternal and fetal prognosis. Therefore, surgery must be considered when counseling patients with congenital heart diseases.

UNITERMS: Pregnancy. Congenital heart disease, newborn.

\section{INTRODUCTION}

I $n$ the past ten years, the decrease in deaths due to heart disease has been expressed as the proportion of women with congenital heart diseases who successfully complete their pregnancies.' Surgical advances in congenital heart disease treatment have diminished risks to the mother and have allowed better fetal development. ${ }^{2}$ However, the main cause of maternal death, besides gestational complications, is still heart disease, congenital or not. ${ }^{3}$

Gestational complication risks depend on the degree of hemodynamic impairment of each clinical situation.

\section{Adress for correspondence:}

Tenilson Amaral Oliveira

Rua Azevedo Jr., 143, apto. 73, bloco 03 - Brás

São Paulo/SP - Brasil - CEP 03040-900
This functional class interferes with the course of the pregnancy, causing maternal death in up to 30 percent of Class IV patients. ${ }^{2}$ Pulmonary hypertension, cyanosis, or ventricular dysfunction are associated with a poor maternal/fetal prognosis, and with a higher incidence of heart failure, pulmonary congestion, arrhythmia and thromboembolisms. ${ }^{4}$

This study analyzes obstetric and perinatal aspects of patients with congenital heart disease in comparison with normal subjects.

\section{MATERIAL AND METHODS}

We studied 100 pregnant women with congenital heart diseases during pregnancy and puerperium. Follow- 
up was started during the first trimester ( 27 cases) or the second trimester ( 73 cases), on average at 18 weeks, and was continued for three months after delivery. All cases were divided in two groups: Group 1 (G1): Patients who had undergone surgery (varying from 1 to 27 years before pregnancy. Mean=10 years); Group 2 (G2): Patients who had not undergone surgery.

Clinical, cardiologic, and obstetric examinations were carried out every 30 days until the thirty-second week. Afterwards, examinations were every 15 days until delivery. Electrocardiograms and echodopplercardiograms were done in the second and third trimester. Fetal ultrasonograms were done in the second trimester and whenever indicated. Prophylactic antibiotic therapy for endocarditis was given to all patients for risk procedures. Death occurring up to three months after delivery was considered a maternal death.

Newborn babies were evaluated as to vitality, height and weight. They were classified as premature or full-term babies and adequate, small, or large in relation to gestational age. Each baby received a cardiologic examination to verify the existence of any congenital heart disease, which would then be confirmed by echodopplercardiography. Twin babies were withdrawn from the study.

Data was analyzed using the chi-square or Fisher's exact test. For the comparison between means, we used Students $t$ test with significance level of 0.05 .

\section{RESULTS}

G1 had an average age of 24 years ( 14 - 36 years), of which 26 were in their first pregnancies. Heart diseases are shown in Table 1. Nine patients from G1 presented residual heart lesions.

\section{CARDIOLOGIC ASPECTS}

\section{Cyanosis and Transvalvar wedge}

Sixteen (16 percent) patients presented cyanosis, of which 2 (4 percent) were in G1 (Eisenmenger's syndrome; right ventricle double outlet) and 14 (27 percent) were in G2 (ES - 11 cases; PS+VIC+AIC- 1 case; right ventricle double outlet - 1 case; AVC+PS - 1 case). Pulmonary arterial hypertension ( $\mathrm{PH}$ ) occurred in 1 case ( 2 percent) in G1, in which a patient with Eisenmenger's syndrome and residual IVC underwent surgery at twelve years. Fifteen (29 percent) patients in G2 (ES -11 cases; AVC +
Table 1

Types of heart anomalies

\begin{tabular}{lll}
\hline Obstructive & 4 & 15 \\
Aortic stenosis & 1 & 6 \\
Coarctation of the aorta & 1 & 2 \\
Subaortic stenosis & - & 1 \\
$\begin{array}{l}\text { Aortic stenosis + coarctation } \\
\text { of the aorta }\end{array}$ & - & 1
\end{tabular}

Pulmonary stenosis

\begin{tabular}{lll}
\hline Abnormal communications and shunts & 21 & 18 \\
Atrial septal defect (ASD) & 8 & 9 \\
Ventricular septal defect (VSD) & $4^{*}$ & 5 \\
Patent ductus arteriosus (PDA) & 4 & 2 \\
Common atrium and ventriculum (CAV) & 2 & 1 \\
AC + IVC + PDA & $1^{*}$ & - \\
IVC + PAC & $1^{*}$ & - \\
IAC + Anomalous pulmonary venous & 1 & 1 \\
connection (APVC) & &
\end{tabular}

\begin{tabular}{lll}
\hline Combined anomalies & 7 & $\mathbf{5}$ \\
PS + IAC & 2 & 1 \\
PS + IAC + IVC & - & 1 \\
PS + IVC & 1 & - \\
PS + AVC & - & 2 \\
Aortic stenosis + PS & - & 1 \\
Aortic stenosis + IVC + PAC & 1 & - \\
Aortic stenosis + PAC & 1 & - \\
Subaortic stenosis + PAC & 1 & - \\
Subaortic stenosis + IVC & 1 & - \\
\hline Cyanotic anormalies & 16 & 14 \\
Fallot's tetralogy & $11^{\star}$ & - \\
Ebstein's anomaly & 2 & 1 \\
Transposition of the great vessels & 1 & 1 \\
Right ventricular double outlet & 1 & 1 \\
Eisenmenger's syndrome & $1^{\star}$ & 11 \\
\hline Total & 48 & $\mathbf{5 2}$ \\
\hline * Residual lesions & &
\end{tabular}

PS - 2 cases; PS+IAC+IVC - 1 case; GAT - 1 case) presented this characteristic $(\mathrm{p}<0.001)$.

Transvalvar wedge was over $50 \mathrm{mmHg}$ in 10 (19 percent) patients in G2: aortic stenosis (5 cases); subaortic stenosis ( 1 cases); coarctation of the aorta ( 1 case); pulmonary stenosis ( 1 case); right ventricle double outlet ( 1 case); aortic stenosis + coarctation of the aorta ( 1 case). One patient ( 2 percent) was in G1 with aortic stenosis $(\mathrm{p}<0.01)$. 


\section{Functional Class}

Most cases ( 85 percent) were classified as functional Class I or II during the first visit. Class III or IV were more frequent ( $\mathrm{p}=0.001$ ) in $\mathrm{G} 2$ ( 14 cases), in comparison to G1 (1 case), corresponding to: Eisenmenger's syndrome ( 3 cases); aortic stenosis ( 2 cases); ACP ( 2 cases); aortic stenosis and coarctation of the aorta ( 1 case); subaortic stenosis (1 case); coarctation of the aorta (1 case); IAC (1 case); PS+VIC+AIC (1 case); AVC (1 case); and right ventricle double outlet ( 1 case). The Class III case in G1 was due to an IAC. Eleven patients evolved from Classes I to II and from III to IV, five of whom were in G1 (IVC 2 cases, Fallot's tetralogy, right ventricle double outlet and aortic stenosis) and six of whom were in G2 (Aortic stenosis - 3 cases, IAC, AVC, and Pulmonary stenosis).

Two patients in G1, with double outlet of the right ventricle in one, and aortic stenosis in the other, underwent heart surgery during pregnancy due to untreatable heart failure.

\section{Maternal Mortality Rates}

Maternal mortality was higher ( $\mathrm{p}=0.02)$ and/or in $\mathrm{G} 2$ ( six deaths $=12$ percent; three during pregnancy and or during puerperium) in relation to $\mathrm{G} 1$, in which no deaths occurred.

Table 2 compares heart disease to functional class, hemoglobinemia, pulmonary hypertension or transvalvar wedge, and death period.
Table 3

Abortions and low-weight newborns

\begin{tabular}{lll}
\hline & Abortions & Low-weight newborn \\
\hline G1 & 2 & 6 \\
$\%$ & $4 \%$ & $13 \%$ \\
G2 & 5 & 18 \\
$\%$ & $10 \%$ & $38 \%$ \\
Total & 7 & 24 \\
& $14 \%$ & $51 \%$ \\
\hline
\end{tabular}

Four (27 percent) maternal deaths occurred among 15 Class III and IV patients. Two ( 2 percent) out of eightyfive Class I and II patients died.

\section{PERINATAL AND OBSTETRIC ASPECTS}

\section{Abortions}

There were a total of seven abortions, of which six were spontaneous and one was therapeutic; two were in G1 and five were in G2 (Table 3). There was no significant difference between the groups (10 vs. 4 percent).

Therapeutic abortion was a measure taken in the first trimester for a Class III patient with Eisenmenger's syndrome. Spontaneous abortions occurred in five Class I/II patients (Eisenmenger's syndrome - 3 cases, Ebstein's Disease - 2 cases) and in a Class III patient with pulmonary stenosis + IAC + IVC).

\section{Table 2}

Maternal Mortality

\begin{tabular}{lllll}
\hline Lesion & $\begin{array}{l}\text { Functional } \\
\text { LClass }\end{array}$ & $\begin{array}{l}\mathrm{HGB}(\mathrm{G} / \mathrm{DL}) \\
(\mathrm{mmHg})\end{array}$ & TVW/PH & Period \\
\hline $\begin{array}{l}\text { Eisenmenger's } \\
\text { syndrome - ES }\end{array}$ & II & 16.4 & 120 & $26 \mathrm{w}$ \\
ES $^{\star}$ & III & 15.4 & 95 & $31 \mathrm{w}$ \\
ES $^{\star}$ & II & 18.7 & 130 & $30 \mathrm{dad}$ \\
Aortic stenosis & III & 12.2 & 120 & $37 \mathrm{w}$ \\
Aortic stenosis & III & 12.5 & 106 & 40 dad \\
Subaortic & III & 12.5 & 86 & 60 dad \\
\hline
\end{tabular}

\section{Low-weight newborns, prematurity and intrauterine growth retardation}

We observed a significant difference $(\mathrm{p}=0.01)$ between the proportion of newborns low-weight neonates in G2 (38 percent) and G1, (13 percent) (Table 3). This did not occur in the group of patients with residual lesions. Only one out of 11 cases with Fallot's tetralogy gave birth to a low-weight newborn. Seven out of eight newborn babies, from Eisenmenger's syndrome cases were low-weight.

TVW - Transvalval wedge

$\mathrm{PH}$ - Pulmonary Hypertension

dad - Days after delivery

HGB - hemoglobin concentration

* Sudden death

w - Week of gestation
Prematurity was more frequent $(\mathrm{p}<0.01)$ in G2 (15 cases $=32$ percent) than in G1 ( 3 cases -7 percent). Intrauterine growth retardation occurred in 6 (13 percent) cases in $\mathrm{G} 1$ and 13 (28 percent) cases in $\mathrm{G} 2(\mathrm{p}=0.08)$. No growth retardation was registered in patients with residual lesions. There was no prematurity in this group, and only 
one of 11 cases of Fallot's tetralogy was associated with intrauterine growth retardation. Five out of eight newborn babies from patients with Eisenmenger's syndrome showed growth retardation, and six were premature.

\section{Anesthesia}

Anesthesia was used during delivery according to the extent of maternal cardiac involvement. Twenty-four (52 percent) patients of $\mathrm{G} 1$ underwent peridural anesthesia. In $\mathrm{G} 2,15$ ( 36 percent) patients were submitted to peridural anesthesia and 17 (40 percent) were submitted to general anesthesia. Eisenmenger's syndrome patients were submitted to general anesthesia.

Five patients did not receive anesthesia since they had spontaneous births. No clinical problems were attributed to the use of anesthesia.

\section{Type of birth}

Twenty-two (48 percent) cases from G1 and 31 (66 percent) from G2 underwent a caesarean section (no significant difference). Table 5 shows the indications of the caesarean deliveries. Type of heart disease was the most important indication in 13 cases, of which eleven were in G2: Eisenmenger's syndrome (4 cases);aortic stenosis ( 2 cases); coarctation of the aorta ( 2 cases);aortic stenosis + coarctation of the aorta (1 case); subaortic stenosis (1 case); and patent ductus arteriosus with a dissecting aneurysm of aorta ( 1 case). Two cases were in $\mathrm{G} 1$; coarctation of the aorta and aortic stenosis.

\section{Fetal and neonate mortality rates}

Two fetal and 5 neonate deaths occurred in G2, and none occurred in G1 ( $\mathrm{p}=0.01)$. Table 6 shows fetal death related to heart disease.

Table 4

Types of delivery

\begin{tabular}{lllll}
\hline Delivery & Normal & Forceps & Caesarean & Total \\
\hline G1 & 11 & 13 & 22 & 46 \\
& $24 \%$ & $28 \%$ & $48 \%$ & $100 \%$ \\
G2 & 9 & 7 & 31 & 47 \\
& $19 \%$ & $15 \%$ & $66 \%$ & $100 \%$ \\
Total & 20 & 20 & 53 & 93 \\
& $22 \%$ & $21 \%$ & $57 \%$ & $100 \%$ \\
\hline
\end{tabular}


Table 5

\section{Caesarean section indications}

\begin{tabular}{lll}
\hline & G1 & G2 \\
\hline Fetal bradycardia & 10 & 11 \\
Functional dystocia & 3 & 1 \\
Pelvic presentation & 2 & - \\
Two previous Caesarean sections & 1 & 2 \\
PMR / induction failure & 3 & - \\
CPD & - & 1 \\
RCIU & - & 1 \\
Post mortem & - & 3 \\
Heart disease & $2^{*}$ & $11^{*}$ \\
Others & 1 & 1 \\
Total & 22 & 31 \\
\hline
\end{tabular}

PMR - Premature membrane rupture

CPD - Cefalo-pelvic disproportion

${ }^{*} \mathrm{p}<0.001$

However, laparotomy poses a higher risk due to anesthesia, hemorrhages, infections, emboli, and pulmonary complications. In heart patients, these risks are higher. ${ }^{9}$ Therefore, congenital heart disease is not an indication for Caesarean section. ${ }^{10}$ Anesthesia does influence the type of birth due to different effects of drugs and anesthesia techniques on each kind of heart disease. Eisenmenger's syndrome, aortic and subaortic stenosis indicated the use of peridural anesthetic to preserve peripheral resistance with an adequate pre-load. Although conduction anesthetic may be used in these patients, it is important to note that a decrease in peripheral resistance, which is frequently associated with a sympathetic block, may diminish pre-load and cause heart failure and sudden death.

In G2, more Caesarean sections were indicated due to heart disease (aortic stenosis, coarctation of the aorta, or Eisenmenger's syndrome), since there were more patients with cyanosis, pulmonary hypertension, and obstructive lesions in the left chambers with high transvalvar wedges. Patients with coarctation of the aorta underwent Caesarean sections, although GOODWIN," contrarily to MENDELSON,${ }^{12}$ reported that there was no risk for these patients during labor, since none of the deaths reported in his study occurred during this period.

There was no significant difference between G1 and $\mathrm{G} 2$ in relation to presence of congenital heart diseases in newborn babies. Three babies (3.2 percent) were born with heart disease, while in normal population this incidence is 1 percent. ${ }^{13}$ WHITTEMORE studied 372 babies from 233 women during three years, 17.9 percent of which were from mothers who did not undergo surgery and 14.2 percent from mothers who underwent surgery. In this study, there was no statistical difference between these two groups. ${ }^{14}$

We noted the appearance of similar diseases (IAC) in G1 descendants. The same malformation was observed by CZEIZEK in seven of 12 cases. ${ }^{15}$ In WHITTEMORE'S study approximately half ( 35 of 60 ) of the malformations were similar to the mother's. ${ }^{14}$ NORA \& NORA noted that 8 percent of congenital diseases were genetic and 2 percent were due to the environment, while 90 percent come from a genetic and environmental interaction. ${ }^{16}$ Although we ruled out medications and diseases that could be responsible for congenital diseases, the small number of cases does not allow a distinction between genetic and environmental factors.

Table 6

Types of lesions, clinical characteristics and fetal and neonatal death

\begin{tabular}{llllll}
\hline Lesion & FC & $\begin{array}{l}\text { HGB } \\
(\mathrm{g} / \mathrm{dl})\end{array}$ & $\begin{array}{l}\text { TVW/PH } \\
(\mathrm{mmHg})\end{array}$ & $\begin{array}{l}\text { NB weight } \\
(\mathrm{grams})\end{array}$ & Death \\
\hline ES & 2 & 17.4 & 96 & 510 & before birth \\
ES* $^{*}$ & 2 & 16.4 & 120 & 700 & $\begin{array}{l}\text { after birth } \\
\text { after birth } \\
\text { ES* }\end{array}$ \\
$\begin{array}{l}\text { Aortic stenosis + Coarctation birth } \\
\text { of the aorta }\end{array}$ & 3 & 15.4 & 95 & 950 & 1680 \\
$\begin{array}{l}\text { Aortic stenosis* } \\
\text { PS + AVC }\end{array}$ & 3 & 12.1 & 57 & 3000 & after birth \\
Right ventricular double & 2 & 12.2 & 120 & 950 & after birth \\
after birth
\end{tabular}

*post mortem caesarean section; TVW=Transvalvar wedge

\#heart surgery at 26th week; $\mathrm{PH}=$ Pulmonary hypertension

$\mathrm{FC}=$ Functional class; $\mathrm{HGB}=$ Hemoglobin concentration

$\mathrm{NB}=$ Newborn 


\section{CONCLUSIONS}

Maternal and fetal prognosis was significantly more positive in patients who experienced operations. Residual surgical lesions did not alter any results. Left obstructive involvement and cyanosis were associated with maternal death and most of the neonate deaths. Maternal, fetal and neonate deaths occurred only among patients who were not operated.

Prematurity and low-weight newborns were significantly higher in patients who were not operated upon.
Eisenmenger's syndrome, aortic stenosis, among the lesions that caused left obstruction, were those with higher maternal, fetal and neonate deaths.

Patients who were not operated underwent Caesarean sections more often due to the severity of their diseases.

The incidence of heart diseases in descendants was three times what is usually expected in the general population, with no difference due to surgical correction.

Our results reinforce the need for family planning in patients with congenital heart diseases, which would include orientation about surgery. Pregnancy is not recommended for patients with Eisenmenger's syndrome and aortic stenosis.

\section{Resumo}

Os benefícios da correção cirúrgica de portadoras de cardiopatia congênita em relação a evolução da gravidez ainda apresentam controvérsias. Estudamos 48 gestantes (idade média=25 anos) com cardiopatias congẻnitas corrigidas (Grupo 1), incluindo 15 lesōes cianogènicas: tetralogia de Fallot (11 casos), anomalia de Ebstein (2 casos), transposiçăo das grandes artérias (1 caso), dupla via de saída do ventrículo direito ( 1 caso) e comparamos com 52 gestantes (idade média $=26$ anos) com cardiopatias congênitas não corrigidas, incluindo 11 casos de Sindrome de Eisenmerger (Grupo 2). Ocorreu maior incidência no grupo 2 de óbitos maternos $(12 \% \times 0 ; p=0,01)$, mortalidade perinatal $(15 \% \times 0 ; p=0,01)$, e prematuridade $(32 \% \times 7 \% ; p<0,01)$. Aborto espontâneo $(4 \% \times 10 \%)$, parto cesárea $(48 \% \times 66 \%)$ e retardo de crescimento intra-uterino $(13 \% \times 28 \%)$ nāo apresentaram resultados estatisticamente diferentes. Concluimos que a correçăo cirúrgica de portadoras de cardiopatia congènita está associada a melhor prognóstico materno e fetal em relação às pacientes com cardiopatias não corrigidas. Portanto, a correção cirúrgica deve ser considerada no planejamento familiar de mulheres com cardiopatia congênita.

\section{REFERENCES}

1. Ueland K. Cardiovascular diseases complicating pregnancy. Clin Obstet Gynecol 1978;21:429.

2. Perloff JK. Pregnancy and cardiovascular disease. In: Braunwald E, ed. Heart disease. Philadephia: Saunders, 1983:1763-81.

3. Sugrue D, Blake S, MacDonald D. Pregnancy complicated by maternal heart disease at the National Maternity Hospital, Dublin, Ireland, 1969 to 1978. Am J Obstet Gynecol, 1981;139:1.

4. Schaefer G, Arditi LL, Solomon HA, Ringland JE. Congenital heart disease and pregnancy. Clin Obstet Gynecol 1968;1:1048.
5. Pontes MD. Abortamento. In: Neme B, ed. Patologia da gestação. São Paulo: Sarvier, 1988:1.

6. Rezende J, Montenegro CAB, Barcelos JM. Abortamento. In: Obstetricia, 4th ed. Rio de Janeiro: Guanabara Koogan, 1982:563,

7. Macnulty JH, Metcalfe J, Ueland K. Doença cardiovascular. In: Burrow and Ferris, eds. Complicações clínicas da gravidez, 2nd ed. São Paulo: Roca, 1983:143.

8. Niswonger JWH, Langmade CF. Cardiovascular changes in vaginal deliveries and Caesarean sections. Amer J Obstet Gynec 1970;107:337.

9. Barnes CG. Heart disease in pregnancy. In: Medical Disorders in Obstetric Practice, 4th ed. Oxford and Edinburgh: Blackwell, 1970. 
10. Metcalfe J, Mcanulty JH, Ueland K. eds. Burwell and Metcalfe's heart disease and pregnancy. Boston: Little, Brown \& Co, 1986:223-64.

11. Goodwin JF. Pregnancy and coarctation of the aorta. Clin Obstet Gynecol 1961;4:645.

12. Mendelson CL. Pregnancy and coarctation of the aorta. Am J Obstet Gynecol 1940;39:1014.

13. Hoffmann JL, Christianson R. Congenital heart disease in a cohort of 19,502 births with long term follow-up. Am J Cardiol 1978;42:641.
14. Whittemore R, Hobbins JC, Engle MA. Pregnancy and its outcome in women with and without surgical treatment of congenital heart disease. Am J Cardiol 1982;50:641-51.

15. Czeizel A, Pornoi A, Peterffy E. Study of children of parents operated on for congenital cardiovascular malformations. $\mathrm{Br}$ Heart J 1982;47:290.

16. Nora JJ, Nora AH. The evolution of specific genetic and environmental counseling in congenital heart disease. Circulation 1978;57:212. 